\title{
Author Index Vol. 64, 1995
}

The abstracts in vol. 64, No. 1-2, 1995, have their own Author Index on p. 106 Abbott, D.H. 140 Agetsuma, N. 167 Agoramoorthy, G. 158 Balko,E.A. 124 Bicca-Marques, J.C. 55 Braga,J. 37 Brereton, A.R. 207 Calegaro-Marques, C. 55 Colell, M. 49, 196 Dixson, A.F. 146 Döbeli, M. 107 Epple, G. 140 Escobar, M. 196 Etter,K. 107 Evans, C.S. 140 Fairgrieve, C. 69 G'⿳⺈,8b,H. 215 Gomendio, M. 225 Hardie, S.M. 192 Hayama, S. 1 Hirasaki, E. 218 HookCostigan, M.A. 180 Hsu,M.J. 158

Itakura, S. 44 Kuederling, I. 140 Kumakura, H. 218 Lucas, P.W. 30 Maestripieri, D. 201 Masataka, N. 132 Matano, S. 218 Maté,C. 196 Nakagawa, N. 62 Nakatsukasa, M. 1 Oda,R. 132 Ogawa, H. 153 Overdorff, D.J. 124 Passamani, M. 163 Preuschoft, H. 1 Pryce,C.R. 107, 140 Rogers, LJ. 180 Roldan, E.R.S. 225 Schwarzenberger, F. 107 Szostek,K. 215 Teaford, M.F. 30 White, F.J. 124 Wright, P.C. 124 231 